\section{Formation of Somatic Embryos from Protoplasts of Coffea arabica $\mathrm{L}$.}

\author{
Mari Tahara, Takeshi Yasuda, Naotsugu Uchida, and \\ Tadashi Yamaguchi \\ Department of Agriculture and Horticulture, Kobe University, Rokko, Kobe \\ 657, Japan
}

Additional index words. coffee, cytokinin, osmolality, somatic embryogenesis

Abstract. Somatic embryos were regenerated from protoplasts isolated from embryogenic callus on young leaf explants from mature coffee trees. Embryos were regenerated on modified Murashige and Skoog medium supplemented with $5 \mu$ M BA. Somatic embryos developed into intact plants. Mannitol at $0.5 \mathrm{~m}$ was adequate as an osmoticum for isolating protoplasts, but subsequent culture required 0.3 m mannitol. A culture system in which osmolality was decreased gradually accelerated formation of colonies and somatic embryogenesis. Chemical name used: N-(phenylmethyl) -1H-purine-6-amine (BA).

Coffee is a perennial crop that is grown commercially in tropical areas. Various attempts have been made to apply in vitro techniques for improving coffee. Staritsky (1 970) reported developing embryos and plantlets on callus tissue derived from internode explants of $C$. canephora Pierre ex Froehner. Sondahl and Sharp $(1977,1979)$ established conditions for formation of somatic embryos from auxininduced leaf callus of $C$. arabica using media with various combinations of auxins and cytokinins. Sondahl et al.(1980) reported isolation of protoplasts from coffee, and Schopke et al. (1987) succeeded in regenerating plants from C. canephora protoplasts. Coffea arabica plantlets have been regenerated from protoplasts, but required elaborate procedures (Acuna and Pena, 1991).

We report a simplified method for preparing and culturing protoplasts from embryogenic callus induced from young leaves of mature $C$. arabica trees, and subsequent formation of somatic embryos from these protoplasts with only cytokinin as a plant growth regulator.

\section{Materials and Methods}

Explants for inducing and culturing embryogenic callus were the second leaves from the apices of mature, greenhouse-grown coffee trees (cv. Typica). Leaves were disinfested for $15 \mathrm{~min}$ in a $1 \%(\mathrm{v} / \mathrm{v})$ solution of sodium hypochlorite containing a few drops of Tween 20 (Sigma, St. Louis), and then rinsed twice with sterile distilled water. The surfacedisinfested leaves were cut into $5 \times 5$-mm pieces in a $1 \%(\mathrm{w} / \mathrm{v})$ solution of sodium ascorbate. The explants were then placed in 50-ml

Received for publication 14 Apr. 1993. Accepted for publication 31 Aug. 1993. This research was supported by a grant-in-aid for special project research from the Ministry of Education, Science and Culture, Japan. The cost of publishing this paper was defrayed in part by the payment of page charges. Under postal regulations, this paper therefore must be hereby marked advertisement solely to indicate this fact. sample tubes containing $15 \mathrm{ml}$ medium, with the abaxial surface in contact with modified Murashige and Skoog (MS) medium (Murashige and Skoog, 1962) that contained the following salts (mg.liter $\left.{ }^{-1}\right): \mathrm{NH}_{4} \mathrm{NO}_{3}, 412.5$; $\mathrm{KNO}_{3}, 475 ; \mathrm{MgSO}_{4} \cdot 7 \mathrm{H}_{2} \mathrm{O}, 92.5 ; \mathrm{KH}_{2} \mathrm{PO}_{4}, 85$; $\mathrm{CaCl}_{2} .2 \mathrm{H}_{2} \mathrm{O}, 110 ; \mathrm{H}_{3} \mathrm{BO}_{3}, 3.1 ; \mathrm{MnSO}_{4} .7 \mathrm{H}_{2} \mathrm{O}$, 11.2; $\mathrm{ZnSO}_{4} \cdot 7 \mathrm{H}_{2} \mathrm{O}, 4.3 ; \mathrm{Na}_{2} \mathrm{MoO}_{4} \cdot 2 \mathrm{H}_{2} \mathrm{O}$, 0.125; $\mathrm{CuSO}_{4} \cdot 5 \mathrm{H}_{2} \mathrm{O}, 0.05 ; \mathrm{Fe} \cdot \mathrm{Na} \cdot \mathrm{EDTA}, 21$; and Gamborg's B5 vitamins (Gamborg et al., 1968). The medium also contained $3 \%(\mathrm{w} / \mathrm{v})$ sucrose and $5 \mu \mathrm{M} \mathrm{BA}$ as the sole plant growth regulator (Yasuda et al., 1985). Before autoclaving, medium $\mathrm{pH}$ was adjusted to 5.7. All cultures were incubated at $25 \mathrm{C}$ with a 14 -h photoperiod of $30 \mu \mathrm{mol} \cdot \mathrm{m}^{-2} \cdot \mathrm{s}^{-1}$ provided by cool-white fluorescent lamps.

After 4 months, yellowish friable calli were apparent on the edges of the explants, and somatic embryos formed 4 weeks after initiation of calli. The callus mass consisted of yellowish friable, brown callus, and somatic embryos. The yellowish material, which had embryogenic potential, was subcultured at 4week intervals on the same medium, and it has retained its embryo-forming capacity for $>4$ years.

Embryogenic calli were collected from the mixture of embryogenic and brown calli and embryos. About $15 \mathrm{mg}$ of cells was incubated in $2 \mathrm{ml}$ of an enzyme solution containing $0.2 \%$ (w/v) pectolyase Y23 (Seishin Pharmaceutical, Tokyo), $1 \%$ (w/v) cellulase Onozuka RS (Yakult Pharmaceutical, Tokyo), and 0.2 to $0.5 \mathrm{~m}$ mannitol on a reciprocal shaker (60rpm) at $27 \mathrm{C}$. After incubation for 2 to $3 \mathrm{~h}$, the suspension containing protoplasts, undigested cells, and debris was filtered through a $33-\mu \mathrm{M}$ nylon sieve, and protoplasts were sedimented by centrifugation at $100 \times \mathrm{g}$ for $3 \mathrm{~min}$. The sedimented protoplasts were resuspended in a solution of $0.5 \mathrm{~m}$ mannitol and $2.5 \mathrm{mM} \mathrm{CaCl}_{2}$, and the suspension was centrifuged at $100 \times g$ for $3 \mathrm{~min}$. The pellet was resuspended in liquid culture medium, and $0.1 \mathrm{ml}$ of the protoplasm suspension was mixed with $1.4 \mathrm{ml}$ of liquid culture medium or culture medium solidified with $0.3 \%$ Gelrite that had been kept at $\approx 40 \mathrm{C}$ in $35 \times 10$-mm plastic petri dishes. In further experiments, the following culture method was adopted to gradually reduce osmolality of the medium.

The agar-containing medium without mannitol, with or without $1 \%$ activated charcoal, was first poured into a $60 \times 10$-mm plastic petri dish and allowed to solidify. A circle of solidified agar medium, $35 \mathrm{~mm}$ in diameter, was then removed from the center of the petri dish. The mixture of protoplasts and Gelrite-containing medium was placed in the circular hole in the solidified medium. In all cultures, protoplasts were cultured at a final density of $10^{5} \%$ ml. Dishes were sealed with Sealon film (Fuji, Tokyo). Modified MS medium was adopted as the basal medium and was supplemented with $3 \%$ (w/v) sucrose, $5 \mu \mathrm{M} \mathrm{BA}, 10 \%$ coconut water (GIBCO, New York), and 0.1 to $0.6 \mathrm{M}$ mannitol ( $\mathrm{pH}$ 5.7). Dishes were placed in plastic boxes to reduce evaporation and incubated in darkness at $25 \mathrm{C}$.

All experiments were conducted twice with five replications per treatment. Plating efficiency was calculated as the estimated number of cell colonies per number of plated protoplasts.
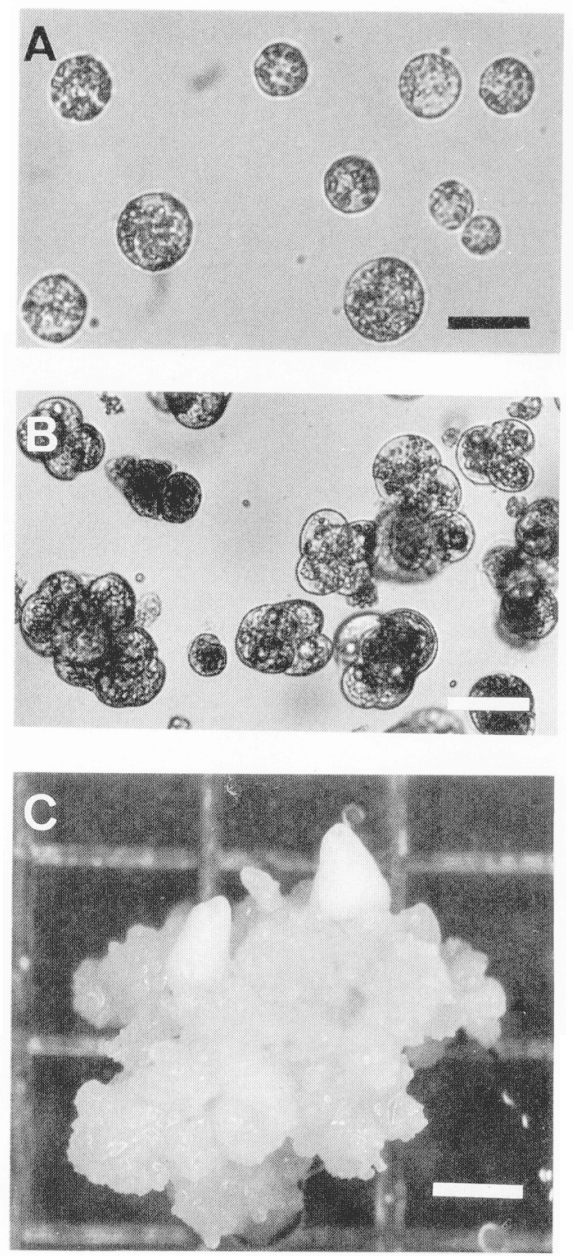

Fig. 1. Protoplasts derived from embryogenic callus of Coffea arabica. (A) Protoplasts in Gelritesolidified medium. Bar $=30 \mu \mathrm{m}$. (B) Formation of cell clusters after 20 days in culture. Bar $=30$ $\mu \mathrm{m}$. (C) Regenerated colony, with somatic embryos, from a protoplasm cultured for 2 months. $\mathrm{Bar}=1 \mathrm{~mm}$. 


\section{Results and Discussion}

Embryogenic callus of coffee was characterized by small clumps of densely cytoplasmic and spherical cells. Embryogenic calli were very friable and easily dispersed in the enzyme solution. Protoplasts were liberated from the outside of cell clumps. Isolated protoplasts were relatively small (10 to $30 \mu \mathrm{M}$ in diameter) and densely cytoplasmic (Fig. 1A).

In the Gelrite-solidified medium, the first division of cells was observed during the third week of culture (Fig. 1B). Adding liquid medium without mannitol every 2 weeks accelerated colony growth. Some colonies produced somatic embryos in the petri dishes after 2 months of culture (Fig. 1 C). In liquid medium, protoplasts aggregated, and their aggregation prevented identification of colonies.

After 2 to 3 months, the Gelnte blocks containing colonies were cut into $\approx 5 \times 5$ - $\mathrm{mm}$ pieces and transferred to $15 \mathrm{ml}$ of medium solidified with $0.9 \%$ agar in $50-\mathrm{ml}$ sample tubes. When the radius of a colony reached $>1$ $\mathrm{mm}$, the colony was subculture again. Somatic embryos on the transplanted colonies that had regenerated from protoplasts are illustrated in Fig. 2A. Somatic embryos developed into plantlets on the medium, as did the original embryogenic calli (Fig. 2B). Protoplastderived plantlets, which grew $4 \mathrm{~cm}$ in height with root, were planted in pots containing sandy loam and placed under high humidity for acclimatization. After 1 to 2 weeks, plants were transferred to a greenhouse and grown into mature plants that bore fruit after 3 years.

The optimum concentration of mannitol for isolating protoplasts was $0.5 \mathrm{M}$ (Fig. 3), but a lower concentration of the osmoticum was required for protoplasm culture (Fig. 4). The immediate change in osmotic pressure that
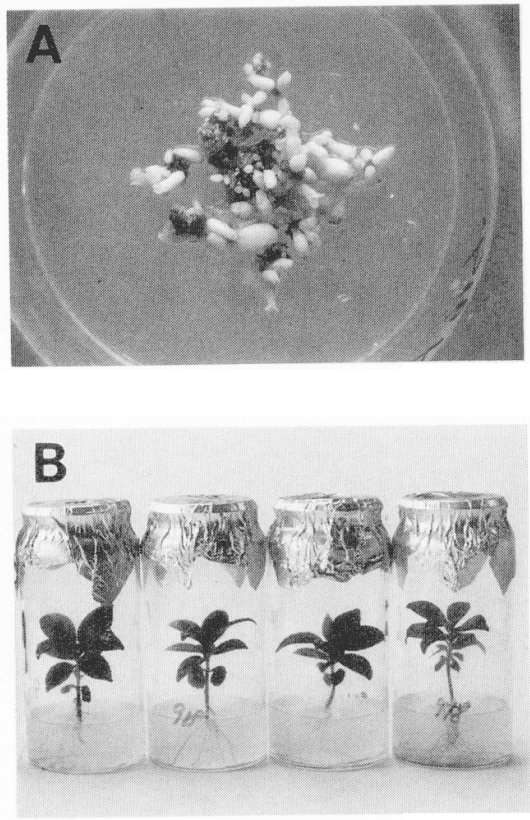

Fig. 2. (A) Somatic embryos of $C$. arabica formed 3 weeks after transfer of a colony onto agarsolidified medium. (B) Plantlets developed from somatic embryos after 8 weeks of culture.

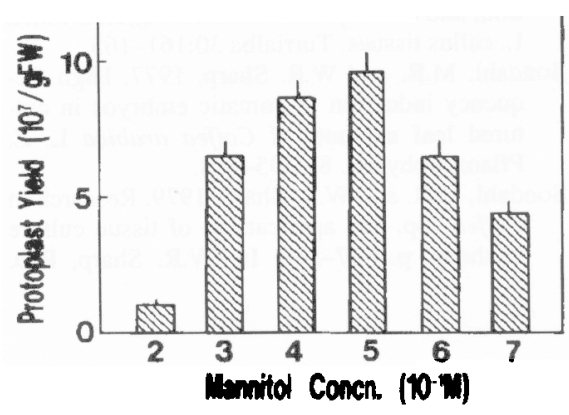

Fig. 3. Effects of mannitol concentration on isolating $C$. arabica protoplasts. Vertical bars represent +1 SE of two trials, each with five replicates per treatment.

occurred when protoplasts were transferred to plating culture decreased protoplasm viability.

Figures 5 and 6 show the results of reducing mannitol concentration in medium and treatment with activated charcoal on formation of macrocolonies ( $>0.5 \mathrm{~mm}$ in diameter) and embryos. Treatments I and III, in which protoplast-plated regions were surrounded by agar-solidified medium without mannitol, promoted macrocolony and embryo formation. This promotion may have been caused by a gradual decrease in osmolality. Adding 1\% activated charcoal to the surrounding medium did not significantly promote the formation of colonies and embryos.

Recently, Neuenschwander and Baumann (1992) described a protocol for somatic embryogenesis in coffee. Their procedure was very complicated, requiring many different media and multiple subcultures. We also found that there are disadvantages to protoplasm culture using liquid medium: protoplasts aggregate, which prevents identification of discrete colonies. However, the system reported herein is very simple, and only one type of medium (modified MS with $5 \mu \mathrm{MBA}$ and gelling agent) is used. Our system may be useful for cell fusion and other genetic manipulations.

\section{Literature Cited}

Acuna, J.R. and M. Pena. 1991. Plant regeneration from protoplasts of embryogenic cell suspen-

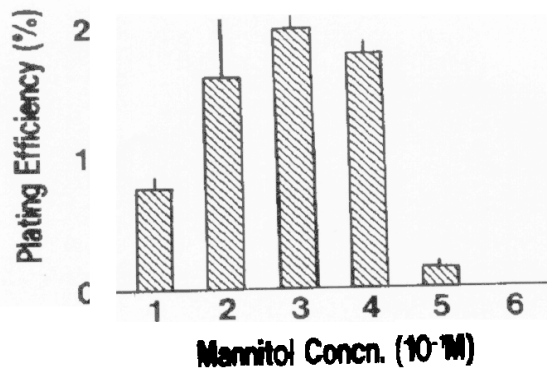

Fig. 4. Effects of mannitol concentration on plating efficiency of $C$. arabica. Plating efficiency was calculated as the estimated number of cell colonies per number of plated protoplasts. Vertical bars represent $+1 \mathrm{SE}$ of two trials, each with five replicates per treatment.

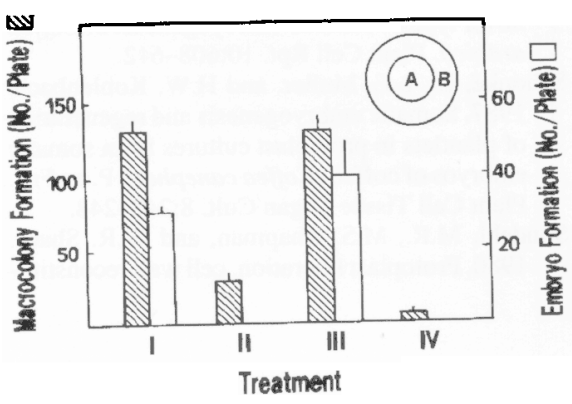

Fig. 5. Effects of reducing mannitol concentration and treatment with activated charcoal on formation of $C$. ambica macrocolonies $(>0.5$ nun in diameter) and embryos after 8 weeks of incubation. Protoplasts $\left(10^{5} / \mathrm{ml}\right)$ were plated on region A in modified MS medium supplemented with 5 $\mu \mathrm{M}$ BA, 0.5 M mannitol, and $0.3 \%$ Gelrite. Region B was filled with $0.9 \%$ agar-solidified, modified MS medium supplemented with $5 \mu \mathrm{M}$ BA (treatment I); $5 \mu \mathrm{M}$ BA plus $0.5 \mathrm{~m}$ mannitol (treatment II); $5 \mu \mathrm{M}$ BA plus $1 \%$ activated charcoal (treatment III); and $5 \mu \mathrm{M}$ BA plus $0.5 \mathrm{M}$ mannitol and $1 \%$ activated charcoal (treatment IV). Vertical bars represent +1 SE of two trials, each with five replicates per treatment.

sions of Coffea arabica L. cv. Caturra. Plant Cell Rpt. 10345-348.

Gamborg, O. L., R.A. Miller, and K. Ojima. 1968. Nutrient requirements of suspension cultures of soybean root cells. Expt. Cell Res. 50: 148-151.

Murashige, T. and F. Skoog. 1962. A revised medium for rapid growth and bioassays with tobacco tissue cultures. Physiol. Plant. 15:473497

Neuenschwander, B. and T.W. Baumann. 1992. A

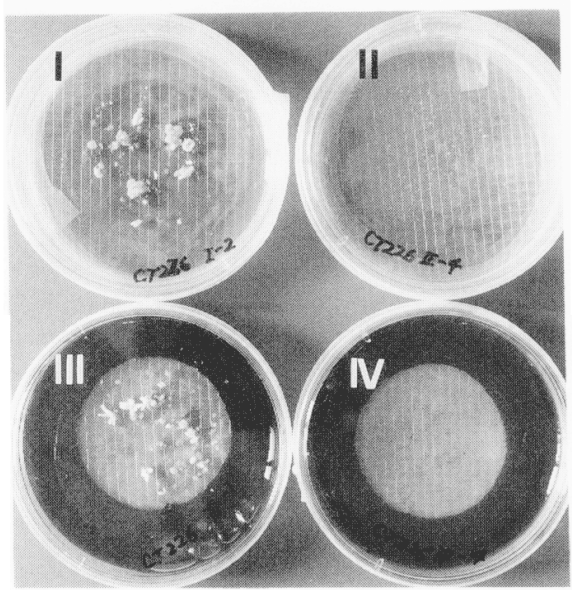

Fig. 6. Effects of reducing mannitol concentration and treatment with activated charcoal on formation of $C$. arabica macrocolonies and embryos after 8 weeks of incubation. Petri dishes were 6 $\mathrm{cm}$ in diameter. Protoplasts $(10 / \mathrm{ml})$ were plated on the central circular region $(35 \mathrm{~mm}$ in diameter) in the petri dish in modified MS medium supplemented with $5 \mu \mathrm{M}$ BA, 0.5 m mannitol, and $0.3 \%$ Gelrite. The rest of the area, which surrounded the central circle, was filled with $0.9 \%$ agar-solidified, modified MS medium supplemented with $5 \mu \mathrm{M}$ BA (treatment I); $5 \mu \mathrm{M}$ BA plus 0.5 m mannitol (treatment II); $5 \mu \mathrm{M} \mathrm{BA}$ plus $1 \%$ activated charcoal (treatment III); and 5 $\mu \mathrm{M}$ BA plus $0.5 \mathrm{~m}$ mannitol and $1 \%$ activated charcoal (treatment IV). 
novel type of somatic embryogenesis in Coffea arabica. Plant Cell Rpt. 10:608-612.

Schopke, C., L.E. Muller, and H.W. Kohlenbach. 1987. Somatic embryogenesis and regeneration of plantlets in protoplasm cultures from somatic embryos of coffee (Coffea canephora P. ex Fr.). Plant Cell Tissue Organ Cult. 8:243-248.

Sondahl, M. R., M.S. Chapman, and W.R. Sharp, 1980. Protoplasm liberation, cell wall reconstitu- tion, and callus proliferation in Coffea arabica L. callus tissues. Turrialba 30: 161-165.

Sondahl, M.R. and W.R. Sharp. 1977. High frequency induction of somatic embryos in cultured leaf explants of Coffea arabica L. Z. Pflanzenphysiol. 81:395408.

Sondahl, M.R. and W.R. Sharp. 1979. Research in Coffea spp. and applications of tissue culture methods, p. 527-584. In: W.R. Sharp, P.O.
Larsen, E.F. Paddock, and V. Raghavan (eds.). Plant cell and tissue culture. Ohio State Univ. Press, Columbus.

Staritsky, G. 1970. Embryoid formation in callus tissues of coffee. Acts Bet. Neel. 19:509-514.

Yasuda, T., Y. Fujii, and T. Yamaguchi. 1985. Embryogenic callus induction from Coffea arabica leaf explants by benzyladenine, Plant Cell Physiol. 26:595-597. 